\title{
AC 2008-324: ENHANCING AND ASSESSING LIFE LONG LEARNING SKILLS THROUGH CAPSTONE PROJECTS
}

\section{Jyhwen Wang, Texas A\&M University}

Jyhwen Wang joined the Department of Engineering Technology and Industrial Distribution at Texas A\&M University in 2001 after working 10 years as a researcher and R\&D manager in steel industry. He teaches mechanical design applications and his research interest is in the areas of mechanical design and material processing technology. He received his $\mathrm{Ph}$. D. degree in mechanical engineering from Northwestern University.

\section{Alex Fang, Texas A\&M University}

Alex Fang is an assistant professor in the Department of Engineering Technology and Industrial Distribution at Texas A\&M University. Prior to joining Texas A\&M, he was an researcher at KBSI in College Station, Texas. He received his Ph.D. in Mechanical Engineering from Texas A\&M University. Dr. Fang's teaching and research interests are in manufacturing processes , nondestructive testing technologies, and acoustic noise reduction.

\section{Michael Johnson, Texas A\&M University}

Johnson is an assistant professor in the Department of Engineering Technology and Industrial Distribution at Texas A\&M University. Prior to joining the faculty at Texas A\&M, he was a senior product development engineer at the 3M Corporate Research Laboratory in St. Paul, Minnesota. He received his S.M. and Ph.D. in mechanical engineering from the Massachusetts Institute of Technology. Johnson's research focuses on the cost modeling and analysis of product development and manufacturing systems. 


\title{
Enhancing and Assessing Life Long Learning Skills through Capstone Projects
}

\begin{abstract}
With rapid advances in new technology, graduates from an engineering technology program have to constantly acquire new knowledge and skills during their professional career. Thus, one of the ABET program outcomes requires students to recognize the need for, and an ability to engage in lifelong learning. In most of the Engineering Technology (ET) programs, capstone projects are designed for students to utilize their technical knowledge, problem solving skills, and project management skills to develop a product or a system related to their discipline. This paper presents a methodology of utilizing the capstone course as a vehicle to enhance and assess student's life long learning skills. During the semester long course, one student team signed up to learn the subject of adhesive technology that is not taught in the current curriculum. The student team designed and built an adhesive test apparatus that can be used for outreach activities. Another student team was assigned to learn rapid prototyping. The student team installed a Fused Deposition Modeling (FDM) rapid prototyping machine and designed and produced FDM parts for demonstrations. To assess student learning, surveys on students' knowledge and skill in adhesive technology and rapid prototyping were conducted at the beginning and the end of the semester. The paper summarizes the survey results and discusses the students' self learning experience.
\end{abstract}

\section{Introduction}

Preparing students to become lifelong learners is one of the most important functions of college education. Lifelong learners are more likely to succeed as they can quickly acquire new knowledge and skills to perform well in their jobs. Therefore, one of the ABET program outcomes requires students to recognize the need for, and an ability to engage in lifelong learning ${ }^{1}$. While engineering or engineering technology programs seldom offer specific course to teach lifelong learning skills, there are various means to prepare students to meet this ABET criterion. One of such means is to provide opportunities to encourage and evaluate self learning. Students who are capable of self learning are better prepared to become a lifelong learners.

This paper reports the experience of using a capstone course as a vehicle to enhance and assess student's self learning skills. Capstone project course which integrates theory, design, and construction is a common requirement for engineering technology programs ${ }^{2}$. In the Manufacturing and Mechanical Engineering Technology (MMET) program at University, the capstone course is designed for students to acquire valuable integrating experience. With the prerequisite, the students enrolled in the course have the required technical competency and the background in fundamentals of project and people management. The projects are normally selected from a list of problems provided by faculty members or industry advisors. In addition to the instructor of the capstone course, a faculty member or an industry advisor serves as a "sponsor" of the project. Student teams are organized to match students' backgrounds and interests with the proposed problems. Student teams, consisting of three to five students per team, make their own decisions on work hours and job assignments. If a project involves implementing the students' design, a budget normally is available from the project 
sponsor, and the student team is given the responsibility to manage the budget. To strengthen students' communication skill, the project teams are required to submit written proposals and progress and final reports. The entire class meets once a week in the scheduled lecture hours so that the teams can give a short presentation of their progress. In this way, the students can learn the factors leading to the success or failure of each of the projects conducted in a 15-week time frame ${ }^{3}$.

In this paper, we describe two capstone projects that engage student teams in self learning. The first team was given a project to learn the subject of adhesion and adhesive technology that is not taught in the current curriculum. The student team was charged to design and build a testing apparatus that can be used for outreach activities. The project description, results, and assessment are reported in Section 2. Another student team was assigned to learn the subject of rapid prototyping. The student team had to install a new Fused Deposition Modeling (FDM) rapid prototyping machine and to design and produce FDM parts for demonstrations. The results and assessment of the rapid prototyping team are reported in Section 3. Section 4 presents the lesson learned from this experience.

\section{Adhesion and Adhesive Technology Project}

\section{$\underline{\text { Project Objectives }}$}

Adhesive bonding is a widely used method to join materials to generate assemblies. It is an alternative to traditional methods of joining materials such as nails, rivets, screws, welding, etc. ${ }^{5,6}$ Adhesive science and technology is multidisciplinary in nature and is not widely covered in engineering technology courses. Nevertheless, it is an important subject that students may find real world applications for in their jobs. The faculty sponsor of the adhesive team received a National Science Foundation (NSF) research grant to conduct research in coating adhesion. To integrate research and education, one of the tasks in the NSF sponsored project is to develop outreach activities that are appropriate for elementary school (K-5) students. The outreach activities are designed to foster K-5 students' interest in science and engineering. With this background, the capstone project objectives were:

- The team members would learn the fundamentals of adhesion science including: adhesion theories, various types of adhesives, mechanical tests of adhesive bond, surface science relating to adhesion.

- The team would design and build an apparatus to demonstrate testing of adhesion bonds. The device would be portable and could be brought to science classes in elementary schools for outreach activities.

\section{Expected Integrating Experience}

The first objective involved student self learning of a new subject while the second objective provided opportunities for students to demonstrate their knowledge and skills in statics, metallic and non-metallic (polymer) materials, strength of materials, CAD and solid modeling, mechanical design, machine elements, manufacturing processes, and project management. It was 
believed that successful completion of the project would allow students to acquire valuable integrating experience.

\section{$\underline{\text { Background Survey }}$}

To assess students' prior knowledge in adhesion and adhesive technology, the entire class was given a survey. The questionnaire consisted of simple questions as follows:

1. My knowledge and skill in adhesion and adhesive technology is ( 1 - no background, $10-$ expert):

2. List a few adhesive application examples in industry.

3. List a few types of adhesives.

4. What are the mechanisms for adhesive bonding?

5. List types of adhesion tests.

6. What is adhesive failure and what is cohesive failure?

7. Why is surface energy important in adhesive bonding?

8. Describe the function of the primer in a coating system?

9. What is the coating on the non-stick cookware? How can the coating adhere to the metal substrate?

10. List the advantage and disadvantage of adhesive bonding vs. mechanical fastener and welding.

The average score for Question 1 was 2.6. The students' self evaluation indicated that their knowledge in the subject area was limited. Four students signed up to work on the project. Their average self evaluation score was 4.6. Examining the answers given in the questionnaire also showed that self learning would be required to improve the response.

\section{$\underline{\text { Project Results }}$}

To emphasize self learning, the faculty sponsor provided minimal guidance to the project team. The team, however, submitted a project proposal and reported progress during the weekly class meetings to meet the capstone course requirement. It was observed that the team performed tasks to achieve both project objectives concurrently. The students researched various types of adhesives using internet and library resources. They also investigated ASTM standards for testing of adhesive bonds. As a result, five adhesives (adhesion mechanism) and three types of testing were considered for apparatus design. The adhesives included: Gorilla glue (polyurethane based glue), two part epoxy, Elmer's glue (polyvinyl acetate based glue), double-sided tape (pressure sensitive adhesive), and Velcro (mechanical interlocking). The team decided to design a device that could be used to test the bonding strength in tensile, shear and cleavage.

With their understanding of adhesion and adhesive testing methods, the students undertook the design of the device for outreach activities. The team was given the contact information of a science teacher at a local elementary school. A meeting with the teacher helped the team to understand the expectation from the grade school teacher. Some design decision making was based on the following considerations: 
- The device would be used in $4^{\text {th }}$ or $5^{\text {th }}$ grade science class to demonstrate the principle of adhesion bonding and testing methods.

- It was expected that the device would be portable and safe to operate in a classroom setting.

- The device would be capable of testing tension, shear, and cleavage; and the load to break the bond would be reasonable.

- The elementary school students would be able to observe the adhesives, the joined specimens, and the load increments during the demonstration.

- A work sheet would be created for the grade school students to follow experimental procedures, make observations, take data, and summarize findings.

The team used Solidwork to construct the model of the testing device. As shown in the rendering in Figure 1, the design consisted of a wooden base, two metal rails at one end, a pulley at the other end, and plexiglass walls for safety. The device was to be positioned on a table or a workbench. For testing, one side of the joined specimen was clamped on the U-channel rail and a cable was attached to an eyelet on the other side of the specimen. The cable was then guided over the pulley and was attached to a set of weights or a bucket (in which weights can be placed) hanging off the ground. The idea was that during the test, weights would be gradually added to increase the load until fracture of the adhesive bond occurred. The setup for shear test was shown in Figures 1 and 2 (where cable should be attached on the left in Figure 2).

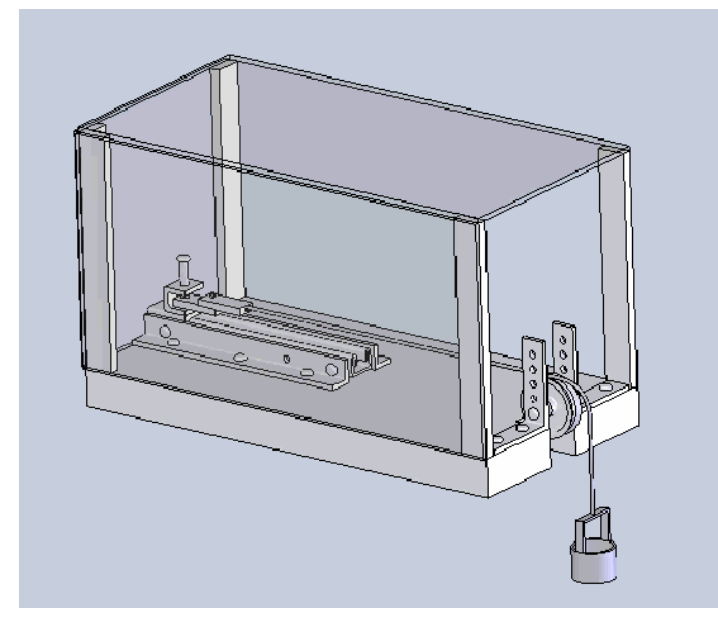

Figure 1. Adhesion test apparatus generated by the capstone project team ${ }^{7}$

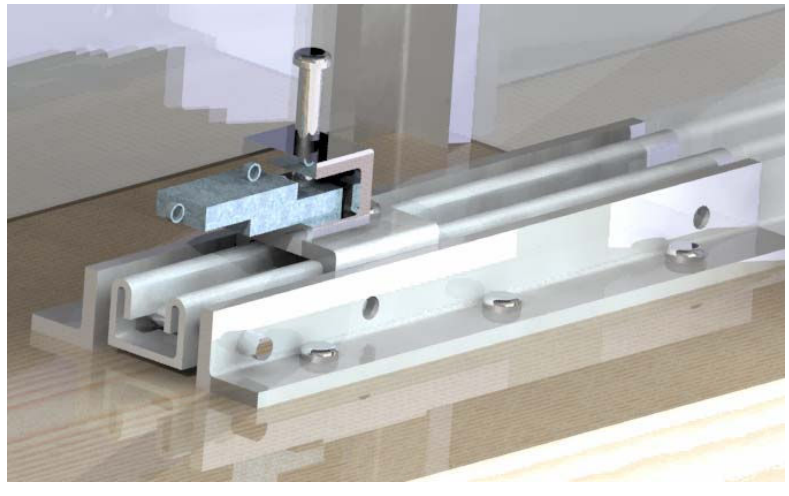

Figure 2 Configuration for shear test ${ }^{7}$

To use the same device for tensile and cleavage tests, the specimen and the metal rail were reconfigured. As shown in Figure 3, a pin connecting the two rails allowed the inner rail to be rotated to a vertical configuration. In this arrangement, the force is acting in the normal direction of the joined surfaces in the tensile test. Figure 4 shows that in the cleavage test the specimen is pulled at an angle (to the adhesive bond surface) determined by the height of the specimen clamping location.

The student team purchased the materials and parts required for the device and used the MMET laboratory facility to manufacture and assemble the device. The actual build time was about one 
week. The team also prepared a work sheet that was suitable for $4^{\text {th }}$ graders to learn simple scientific methods and data collection. Upon the completion of the device, the team visited the $4^{\text {th }}$ grade science class. With the science teacher and faculty sponsor attending, the students gave a successful presentation. The developed device can be seen in the photo (Figure 5) taken during the presentation. The successful outreach visit prompted an invitation to return to the elementary school the following semester. The team also gave a final presentation in the capstone project class and submitted a project report at the end of the semester.

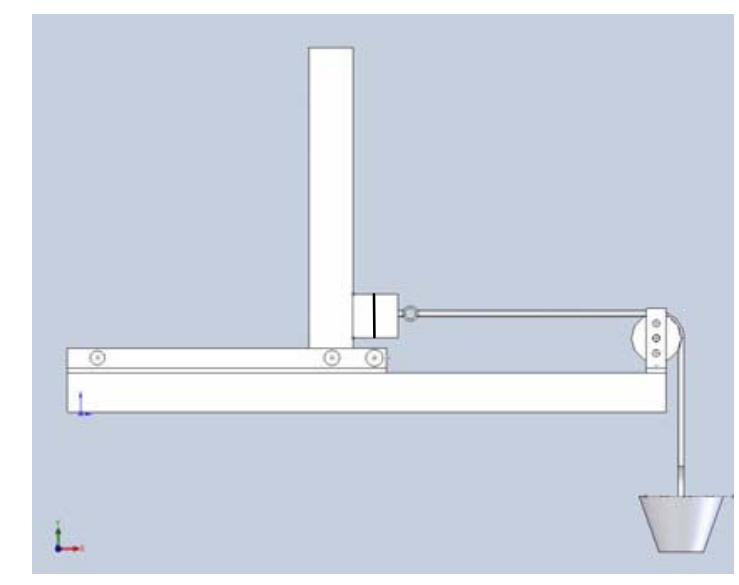

Figure 3 Configuration for tensile test ${ }^{7}$

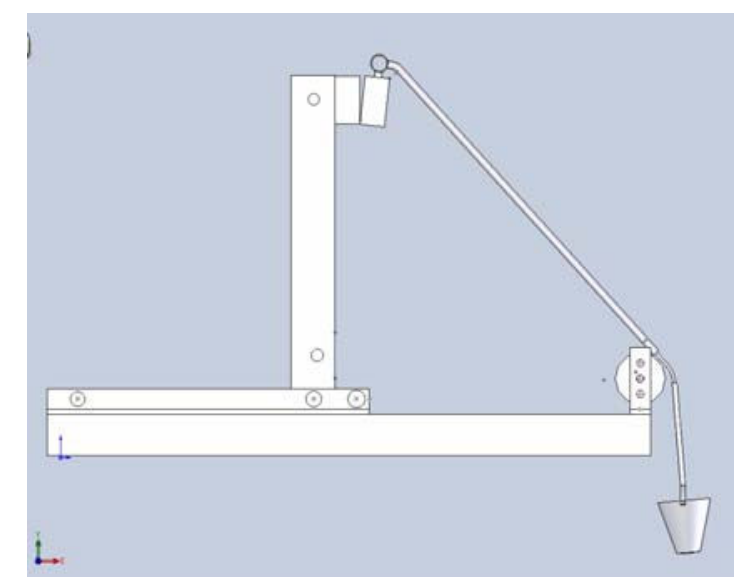

Figure 4 Configuration for cleavage test ${ }^{7}$

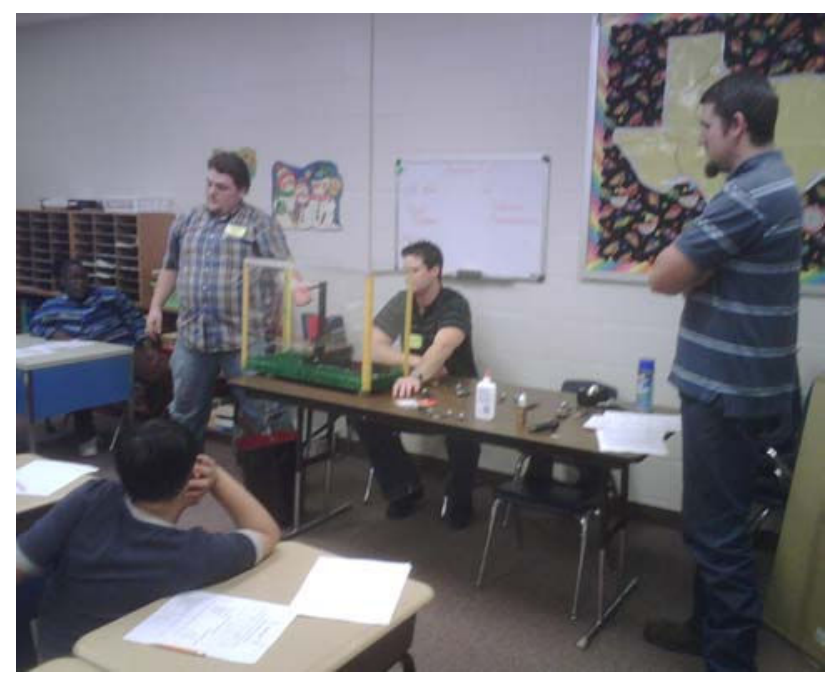

Figure 5 Use of the device in an outreach presentation

\section{$\underline{\text { Self Learning Assessment }}$}

As there were two objectives in this project, assessments could be conducted separately. The first assessment concerned the students' ability to apply the knowledge and skills they acquired earlier to successfully complete a capstone project. Although a detailed assessment was conducted by the capstone course instructor and is not reported in this paper, it is evident that the 
student team had designed and constructed a workable device on time and within budget. The knowledge and skills in metallic and nonmetallic materials, mechanics of materials, manufacturing processes, mechanical design, CAD/CAM, and project management have been utilized. For the second assessment, the primary question to be answered was that if the students could learn the subject of adhesion on their own and demonstrate what they had learned.

At the end of the semester, the team members voluntarily filled in the same questionnaire given in the beginning of the semester. It was found that the average self evaluation score was 7.1 compared to 4.6 (and the class average of 2.6) in the beginning of the semester. The responses to the questions were also improved. Several other indirect observations also indicate that the students achieved an adequate level of learning:

- It was observed that the team could engage grade school students to discuss types of adhesives, testing methods, experimental procedures, and data collection and interpretation.

- The team selected and prepared different types of adhesives for the outreach presentation demonstrating that they had some basic knowledge of polymer chemistry. Velcro was used to demonstrate the mechanical interlocking theory of adhesion.

- The team learned different ASTM adhesion test methods and designed an apparatus that can perform tests resembling the tensile, shear, and cleavage tests.

- It was found that the students made a reasonable effort to acquire knowledge that was not previously taught. In the reference section of the final report, the students listed the library and internet resources used in the project.

One possible weakness of this self learning experience is that the students might not acquire knowledge with significant depth. This is reflected in the self evaluation that the students were reluctant to give themselves a higher score. It is understandable as the capstone course is a 2credit hour course and students would not be able to put the same amount of time as they would for a 3-credit hour course.

\section{Rapid prototyping project}

\section{Project Objectives}

For years, industry has strived to produce physical prototypes to demonstrate and promote new and innovative products. A result of the effort is the development of rapid prototyping (RP) technologies [8]. Rapid prototyping technologies allow designers to build physical parts from CAD models in a short period of time. As rapid prototyping machines have become more affordable, many companies have adopted the technology to improve their design and engineering processes. Among the various RP technologies commercially available, Fused Deposition Modeling is one of the most common additive RP technologies. The process involves melting polymer filament and extruding the semi solid melt through a nozzle. With computer control of the nozzle movement, a part is built strand by strand and layer by layer. Although RP technologies are introduced in most of the manufacturing processes textbooks, MMET students were not familiar with the technologies as the program did not have a rapid prototyping facility. Prior to the start of the capstone course, the Department purchased two FDM rapid prototyping machines. With this new purchase, the objectives of the project were: 
- The student team would install one of the FDM RP machines in the Computer Aided Manufacturing laboratory. The students would acquire the skills to use the software to process CAD files and submit jobs. The team would also learn how to operate the machine including start-up, shut-down, and maintenance.

- The students would use the acquired knowledge to design and develop two laboratory exercises. The developed material will be made available to faculty members to evaluate, revise if necessary, and integrate into courses for future students the gain rapid prototyping experience.

\section{Expected Integrating Experience}

To successfully complete this project, the students were expected to integrate their knowledge and skills in polymer materials, strength of materials, CAD and solid modeling, computer-aided manufacturing, and project management. It was clear that the student team would need to work with the vendor and the faculty and staff in the Department. Therefore, team building, project scheduling, and interpersonal skill were important elements of the project.

\section{$\underline{\text { Background Survey }}$}

To assess students' prior knowledge in rapid prototyping technologies, the entire class was given a survey. The questionnaire consisted of simple questions as follows:

1. My knowledge and skill in rapid prototyping technology is (1 - no background, $10-$ expert):

2. What is rapid prototyping?

3. List a few rapid prototyping technologies you are aware of.

4. What are the typical input and output of a rapid prototyping machine?

5. What is the Fuse Deposition Modeling (FDM) process?

6. With the same plastic material, can parts produced from FDM process be as strong as parts produced from injection molding? Why?

7. Describe the properties of an isotropic material and the properties of an orthotropic material.

8. Why the deposition path (and thus deposition strategy) can influence the mechanical properties of the parts produced from FDM process?

9. Identify the situation that the additive rapid prototyping technologies are more attractive compared to the conventional machining process.

The average score for Question 1 was 2.0. The students' self evaluation indicated that their knowledge in the subject area was limited. There were four students signed up to work on the project and their average self evaluation score was 2.5 . Therefore, it was believed the subject was appropriate for student self learning.

$\underline{\text { Project Results }}$ 
The students assumed project responsibilities immediately after forming the team. Installation considerations include availability of space, electrical power source, and computer network connections. The team worked with departmental staff to request an area in the CAM lab, secure a heavy duty workbench (to put the machine on), and acquire a cabinet for storage of supplies. Once the machine arrived, the team unpacked the shipment, put the machine in the planned location, and completed the hardware installation. The vendor's service engineer visited the campus a few days later to install the software and verify the setup. It was observed that the students were able to quickly pick up some basic functions in the software and test out the machine by building some simple parts. With that experience, the students drafted a standard operations procedure. Since the deposition chamber is hot and the as-built parts should be handled with gloves, a list of safety precautions was also generated.

The FDM RP machine builds Acrylonitrile butadiene styrene (ABS) parts on a water soluble support material. The students found that it was difficult to wash away the support material with hot water alone. The team recommended the purchase of an agitating water tank to 'clean' the parts. The team also took the initiative to develop a "display case" to showcase the parts (some shown in Figure 6) that were built by the machine. While building a thin-walled part, the students found that the build material could not stay on the build pallet due to distortion. The problem led the students to further investigate the deposition process. Through the vendor's website, the team obtained the information to resolve the problem and subsequently generated a trouble shooting guide. The students also learned other techniques to build better (stronger and more accurate) parts [9]. A lab exercise (procedure and worksheet) was also created for ENTC 380 Computer Aided manufacturing course.
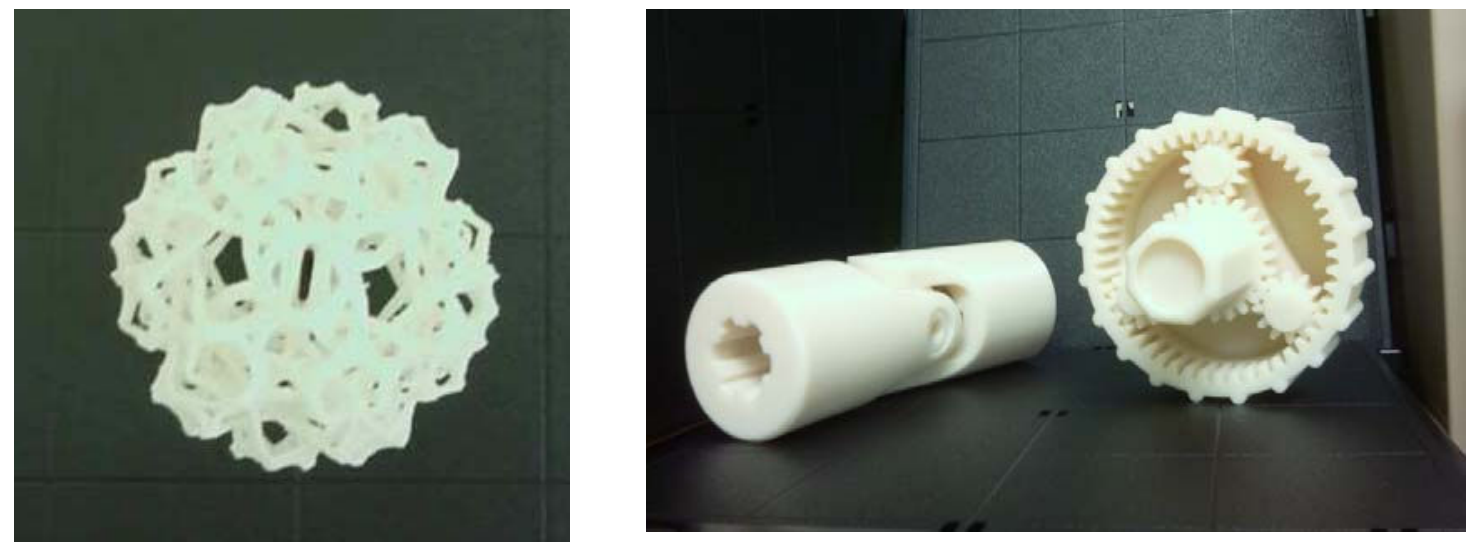

Figure 6 Parts built by a Fused Deposition Modeling rapid prototyping machine ${ }^{10}$

One of the interesting characteristics of the FDM part is that it exhibits anisotropy. Depending on the nozzle trajectory, the process creates parts with different mechanical properties in different direction (Figure 7). To demonstrate this characteristic, the students built tensile test specimens using different build sequences. Instead of controlling the nozzle movement, the students designed tensile test specimens to be built in different direction as shown in Figure 8. The specimens were tested in laboratory and the mechanical properties in different directions were reported. It was observed that the FDM parts had characteristics similar to those of composite materials. The faculty sponsor provided additional reading materials in constitutive modeling for students to understand isotropic, orthotropic, and anisotropic materials models. The material 
testing experience was organized into a laboratory exercise for ENTC 376 Strength of Materials course. As all other teams in the capstone project course, the team gave a presentation and submitted a final report at the end of semester.

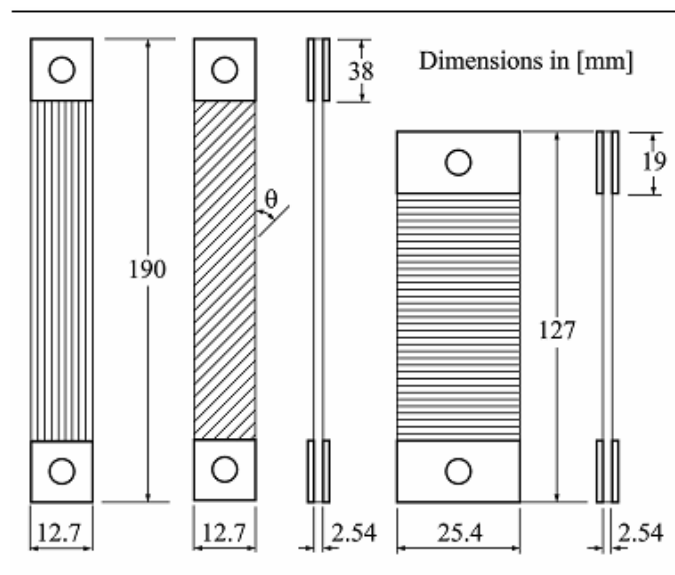

Figure 7 Different deposition sequences for FDM parts ${ }^{11}$

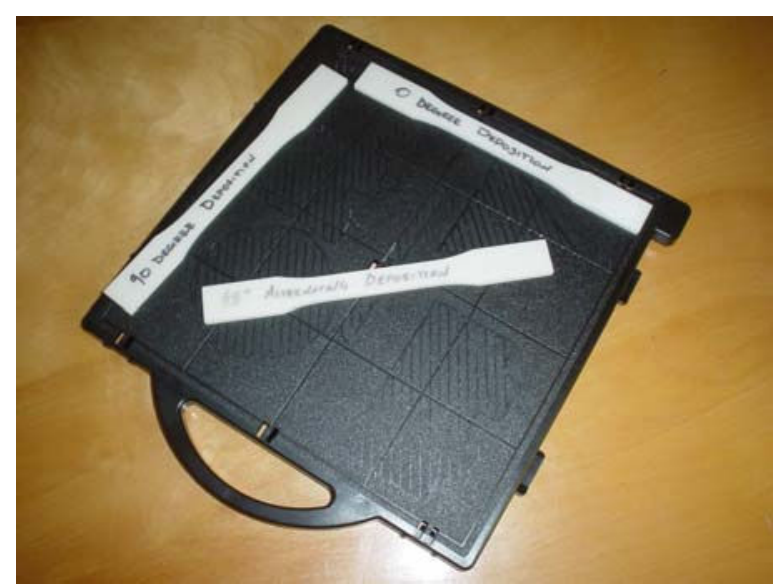

Figure 8 Tensile test specimens ${ }^{10}$

\section{Self Learning Assessment}

Similar to the adhesion project, the RP capstone team had to learn a new subject and integrate the new skill with their previously-acquired knowledge and skills to complete the project. The integrated knowledge and skills included polymer materials, strength of materials, $\mathrm{CAD} / \mathrm{CAM}$, and project management. From the capstone project point of view, the only deliverable not accomplished was the construction of a display case. However, the planning and collection of samples were completed as shown in Figure 9.

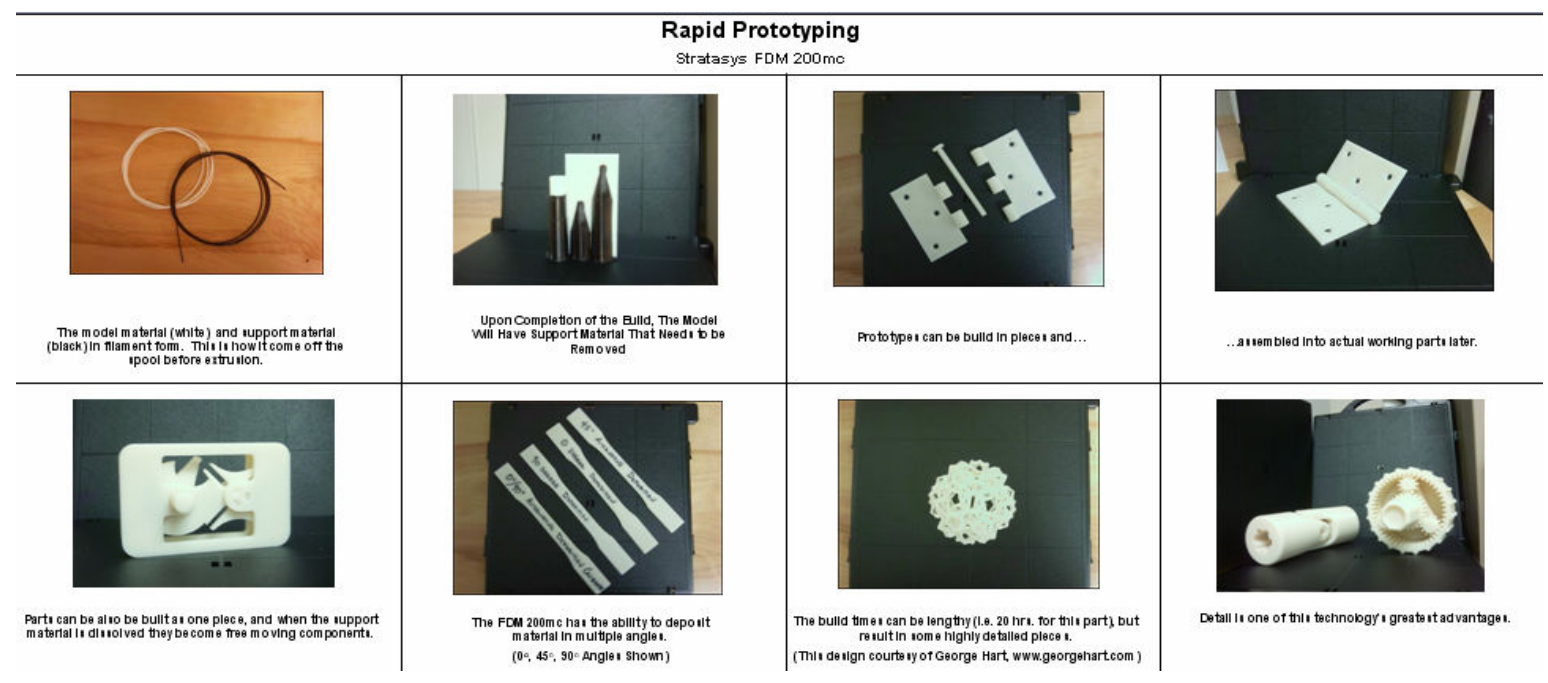

Figure 9 Design of a display case ${ }^{10}$ 
Students' self learning of operating FDM machine and acquiring the software skills was evident. At the end of the semester, only one student volunteered to fill out the questionnaire. The self evaluation score was 7. Other observations of student self-learning included:

- When students sought advice, the faculty sponsor often provided a general direction for the students to proceed.

- The students made a reasonable effort to learn the new software and produce the build files from the CAD/STL files.

- It was observed that the team was able to use internet resources to identify potential solution for the problems they were facing.

- The students were capable of identifying the advantages and disadvantages of FDM in practical applications.

As the student team was very focused on the FDM process and the machine installation, no effort was made in learning other rapid prototyping technologies. The narrow focus could be considered as a weakness in this self-learning experience. Due to limited time the students could devote to the project, learning of material modeling and FDM part performance was barely adequate.

\section{Lesson learned}

It is believed that enhancing students' self-learning skills can better prepare students to become life-long learners. This paper presents an approach of using a capstone project course as an instrument for engineering technology students to engage in self-learning. The student teams were organized to learn a new subject and to apply and integrate the newly-acquired knowledge and skills to complete relevant projects. It was found that the students were willing to take the challenge as they voluntarily signed up to work on the projects. Although the experience is positive, several changes could be made to potentially improve student learning and outcome assessment. The current capstone course is a 2-credit hour course. It was observed that the students were not able to achieve the depth expected by the faculty sponsor. A 3-credit hour capstone project course may improve the self-learning results. As the project outcome is a result of teamwork, individual student learning was not assessed. Future implementation may include individual interviews to better understand individual learning. Nevertheless, positive selflearning results can be found from the work accomplished by the students in both projects. It is believed that including self-learning in the capstone project courses should be encouraged.

\section{Reference}

1. Criteria for Accrediting Engineering Technology Programs, ABET Technology Accreditation Commission, ABET, Inc. Baltimore, MD, 2004.

2. Mirman, C. R., "An Engineering Technology Capstone Course Which Integrates Theory, Design, and Construction in an Open-Ended Project," Proceedings of the 2005 ASEE Annual Conference and Exposition, Section 1648, June 2005.

3. Wang, J., Liu, S., and Price, A. H., "The Dancing Marionette - An Interdisciplinary Capstone Design Experience for Engineering Technology and Computer Science Students," ASEE Annual Conference, June 1821, 2006, Chicago, Illinois. 
4. Pocius, A. V., Adhesion and Adhesives Technology - An Introduction, Hanser Verlag, 2002.

5. Gerhard Gierenz, Werner Karmann. “Adhesives and adhesive tapes”, 2001, New York.

6. Philippe Cognard. "Handbook of adhesives and sealants", 2003, New York.

7. Phillips, J., Adams, B., Borth, R., and Mille, P., Senior Project final Report - Adhesion and Adhesives Technology, Manufacturing and Mechanical Engineering Technology Program, Technology and Industrial Distribution, Texas A\&M University, 2007.

8. Jacobs, P. F., Stereolithography and other Rapid Prototyping and Manufacturing Technologies, ASME Press, 1996.

9. FDM Best Practices, Stratasys, 2005, Eden Prairie, MN.

10. Moreno, C., Jamison, J., Schwee, L., and Guarnieri, S., Senior Project final Report-Rapid Prototyping, Manufacturing and Mechanical Engineering Technology Program, Department of Industrial Distribution, Texas A\&MI University, 2007.

11. Rodriguez, J. F., Thomas, J. P, and Renaud, J. E., "Mechanical behavior of acrylonitrile butadiene styrene (ABS) fused deposition materials. Experimental investigation," Rapid Prototyping Journal, v. 7 (3), pp. 148-158, 2001. 